\title{
Common Errors in Punctuation in Official Document
}

\author{
Shaoshan Liu \\ Tropical Crops Genetic Resources Institute, Chinese Academy of Tropical Agricultural Sciences, Danzhou \\ Hainan, 571737, China
}

Keywords: Punctuation, Common errors, Official document.

\begin{abstract}
Punctuation is a tool for helping texts recording language. Punctuation marks are both formatted and grammatical, and their normative use is especially important. The author collects non-normative and improper use of punctuation marks encountered in the daily document processing and summarizes three kinds of 16 common punctuation errors.
\end{abstract}

\section{Five kinds of common errors in titles}

\section{Use of title mark}

\section{Example 1}

Notice of Tropical Crops Genetic Resources Institute, Chinese Academy of Tropical Agricultural Sciences on Forwarding "Office of the Chinese Academy of Tropical Agricultural Sciences Conducting Collecting Inspections on Safety Production” (wrong)

Notice of Tropical Crops Genetic Resources Institute, Chinese Academy of Tropical Agricultural Sciences on Forwarding Office of the Chinese Academy of Tropical Agricultural Sciences Conducting Collecting Inspections on Safety Production (right)

Analysis: it is stated that in current Practice Directions on Documentation in State Administrative Bodies, titles of official document, except to laws and regulations, usually do not use the title mark. The content of the notice is not about laws or regulations, the title mark shall be removed.

\section{Use of period in case of a line break in subtitle}

\section{Example 2}

(1) Completion situation of basic indicators in the first half of the year.

In the first half in 2017, the total funding income is 64.05 million Yuan, increasing by 1.38\% compared to the same period of last year of 63.175 million Yuan, of which ... ... (wrong)

(1) Completion situation of basic indicators in the first half of the year

In the first half in 2017, the total funding income is 64.05 million Yuan, increasing by 1.38\% compared to the same period of last year of 63.175 million Yuan, of which, (right)

Analysis: in case of a line break, the subtitle does not use a period, and in case of use of a period, paragraph break is not required.

\section{Improper use of Arabic numerals when indicating the order}

\section{Example 3}

1, Design work of botanical garden concept planning, navigation map, runway diagram, VI system has entered the stage of site survey and preliminary design, and is expected to complete all the design content and put into production by the end of July. (wrong)

1. Design work of botanical garden concept planning, navigation map, runway diagram, VI system has entered the stage of site survey and preliminary design, and is expected to complete all the design content and put into production by the end of July. (right)

Example 4

(1), Improve the conditions construction of field genebank. (wrong)

(1) Improve the conditions construction of field genebank. (right) 
Analysis: in case of indicating the order, Chinese or Arabic numerals that order with the brackets do not use dot mark and Arabic numerals and Latin letters without brackets use the lower corner point (center point).

\section{Non-normative use of brackets in case of indicating the year and number of publication}

\section{Example 5}

$$
\begin{aligned}
& \times \text { [2017] No.5 (wrong) } \\
& \times \text { 〔2017〕 No.5 (right) }
\end{aligned}
$$

Analysis: in case of indicating the year and number of document publication, use the hexagonal brackets.

\section{Nine kinds of common errors in the text}

\section{Use of comma in case of multiple book names or quotation marks paralleling}

\section{Example 6}

Office organizes to amend and develop 24 systems including, "Measures for the Implementation of Three Importance and One Greatness Policy-making System”, "Internal Control Procedures”, “Attendance Management Approach”, “Research Funding Management Approach”. (wrong)

Office organizes to amend and develop 24 systems including, "Measures for the Implementation of Three Importance and One Greatness Policy-making System” "Internal Control Procedures” “Attendance Management Approach” “Research Funding Management Approach”. (right)

\section{Example 7}

Technology tracking service projects, including, "Hainan Cattle Hybrid Improvement Technology Research”, "Beef Cattle Feed Resources Development and Utilization of Technology Research", "Under-forest Economy (Rubber Seed Medicine Chicken) Technology Integration and Demonstration Base Construction”, and organize South China medicinal plants planting training course. (wrong)

Technology tracking service projects, including, "Hainan Cattle Hybrid Improvement Technology Research" "Beef Cattle Feed Resources Development and Utilization of Technology Research" "Under-forest Economy (Rubber Seed Medicine Chicken) Technology Integration and Demonstration Base Construction”, and organize South China medicinal plants planting training course. (right)

Analysis: between the coordinative constituents with the title and quotation marks, comma is usually not used. If there are other components inserted between parallel quotation marks or title marks, it is appropriate to use comma.

\section{Non-normative use of connective in case of indicating marking the numerical value and the start and end years}

\section{Example 8}

Formulate and implement "Thirteenth Five-Year" economic development plan (2016-2020) of Tropical Crops Genetic Resources Institute, Chinese Academy of Tropical Agricultural Sciences. (wrong)

Formulate and implement "Thirteenth Five-Year" economic development plan (2016-2020) of Tropical Crops Genetic Resources Institute, Chinese Academy of Tropical Agricultural Sciences. (right)

\section{Example 9}

Breed 2-3 new varieties, and develop 10-15 hot wood products. (wrong)

Breed 2 3 new varieties, and develop 10 15 hot wood products. (right)

Analysis: in case of marking the beginning and end of time and region, generally use a short line (accounting for a character position), and in case of marking the numerical range, generally use a short wavy line. 


\section{Use of comma in parallel clauses}

\section{Example 10}

Functional departments shall perform their own duties and cooperate with each other during report material finishing work. The department of science and technology is responsible for promoting the scientific and technological innovation; the department of base and conditions construction is responsible for strengthening conditions support; the department of results transformation is responsible for speeding up the transformation; the department of human resources is responsible for talent team building; the office is responsible for improving the political security and improve the management system. (wrong)

Functional departments shall perform their own duties and cooperate with each other during report material finishing work; The department of science and technology is responsible for promoting the scientific and technological innovation; the department of base and conditions construction is responsible for strengthening conditions support; the department of results transformation is responsible for speeding up the transformation; the department of human resources is responsible for talent team building; the office is responsible for improving the political security and improve the management system. (right)

Analysis: comma cannot be used for leading or summarizing several parallel clauses separated by semicolons.

\section{Use of semicolon after use of period in the parallel clauses}

\section{Example 11}

At present, pursuing-A work is promoted in an orderly manner, and has made some new progress. First, the system construction. All kinds of management systems, training manuals, plans and other materials preparation and revision have completed $40 \%$, and are expected to be completed before August; second, the hardware facilities. Botanical garden new gate visitor center and shopping center construction is basically completed, and expected to put into use before October. (wrong)

At present, pursuing-A work is promoted in an orderly manner, and has made some new progress. First, the system construction. All kinds of management systems, training manuals, plans and other materials preparation and revision have completed $40 \%$, and are expected to be completed before August. Second, the hardware facilities. Botanical garden new gate visitor center and shopping center construction is basically completed, and expected to put into use before October. (right)

Analysis: When the clause or sub- clause listed have used period, the end of each clause cannot use semicolon.

\section{Improper use of punctuation marks at the end of the sentence within brackets}

\section{Example 12}

In order to improve the level of safety production and work and ensure the safety of scientific research work, it is decided to set up the leading group of safety production (the head of the leading group shall be concurrently appointed by the director, and the deputy head shall be concurrently the leader in charge of the safe production work.), to unify safety production work. (wrong)

In order to improve the level of safety production and work and ensure the safety of scientific research work, it is decided to set up the leading group of safety production (the head of the leading group shall be concurrently appointed by the director, and the deputy head shall be concurrently the leader in charge of the safe production work), to unify safety production work. (right)

Analysis: question marks, exclamation points, and ellipses can be used when required at the end of the sentence within brackets. In addition to this, punctuation marks are usually used at the end of the sentence within brackets.

\section{Use of pause mark between approximate numbers}

\section{Example 13}

Three, four meters; six, seventy plants; one, two hundred types; sixteen, seven pieces (wrong) 
Three or four meters; sixty or seventy plants; one or two hundred types; sixteen or seventeen pieces (right)

There is no phonetic pause in the middle of the two numbers representing approximate number, so it is not separated by a pause mark.

\section{Use of period at the end of texts for the figure or table}

\section{Example 14}

(The figure or table is omitted)

Note: The deadline for the above statistics is June 30, 2017; new varieties refer to access to new plant species authorization; patent refers to the patent license. (wrong)

Note: The deadline for the above statistics is June 30, 2017; new varieties refer to access to new plant species authorization; patent refers to the patent license (right)

Analysis: comma can be used in short text description text for the figure or table, but the end of the text cannot be followed by a full stop. Even if sometimes the text is longer, a full stop is used in the preceding paragraph, and still cannot be used at the end of the text.

\section{Two kinds of errors at the end of text}

\section{Use of reference number after inquiry language in requisite document}

\section{Example 15}

The above request is proper or not? Please indicate. (wrong)

The above request is proper or not, please indicate. (right)

Analysis: "proper or not", "should or not", or "can or not" is the commonly used inquiry language in requisite document, question mark is not used at the end, but the comma.

\section{Use of punctuation marks after appendix name}

\section{Example 16}

Appendix: 1. Collection table of dangerous chemicals waste liquid of Tropical Crops Genetic Resources Institute; (wrong)

Appendix: 1. Collection table of dangerous chemicals waste liquid of Tropical Crops Genetic Resources Institute (right)

Analysis: any punctuation mark cannot be used after the appendix name.

\section{Conclusions}

The above common punctuation marks use errors and analysis are expected to provide some inspiration and help for fellows engaging in secretary work and paperwork with the drafting or review of official documents. For details of the use of punctuation marks in official documents are not covered in this paper, please refer to the relevant standards and provisions of currently issued "Regulations for Handling Official Documents of the Party and Government" and the matching "National Standard for Official Documents of the Party and Government” (2012 Edition).

\section{References}

[1] Liu Lingbing, Causes and Countermeasures on Non-normative Phenomenon in Official Document Writing, Office Business. 2016 (01).

[2] Li Zaifa, Example Analysis on Improper Use of Common Punctuation in Official Document Writing, Application Writing, 2014 (11).

[3] Shuo Ying, Correct Use of Punctuation, Friends of the Secretary .2014 (12). 
[4] Zhang Yan, Implementation of National Standards Seen from "Regulations for Handling Official Documents of the Party and Government" and "Format of Official Documents of the Party and Government”, Journal of Dalian University. 2014 (02).

[5] Huang Biyun, The Problem of Punctuation in Official Document Writing, Secretary. 2011 (06).

[6] Ni Renan, Use of Punctuation in Title of Official Document, Friends of the Secretary. 1997 (24). 